\title{
LA DEUDA EXTERNA
}

\section{Víctor Cristian Martínez}

Profesor en la Universidad de Córdoba, Argentina.

\section{CAUSAS Y NATURALEZA DEL ENDEUDAMIENTO}

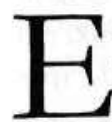

n 1823 fue creado el consulado inglés en Argentina, cuya titularidad le fue encomendada a un funcionario subalterno del Foreign Office, y todo lo referente al crédito de la Baring Bros. pasó por dicho funcionario quien escribió que por suerte en Argentina se estudiarían elementos de economía y su conocimiento les aseguraría en el futuro funcionarios inteligentes que sabrían ciertos principios como, por ejemplo, que el correcto pago de las deudas es el fundamento de las riquezas.

Es decir que habría ciertos servidores del Estado quienes, a pesar de ser argentinos, pondrían todo su empeño-gracias a las lecciones de economía liberal-y, en consecuencia, pagarían estrictamente la deuda externa; o sea que se pasaría del odioso "yugo español" a la "suave protección inglesa".

Esta suave protección ahora la ejercen los Estados Unidos. Vemos así que existe una tradición escolástica favorable a las enseñanzas liberales y de repudio a las de carácter proteccionista o industrializadores.

A principios del siglo XX, el empréstito fue cancelado con una retribución superior al mil por ciento del capital nominal, que jamás fue remitido a nuestro país. En la década de los setenta los países del Medio Oriente elevaron de 80 centavos de dólar a 15 
dólares el barril de petróleo. Estos países llevaron esta fenomenal disponibilidad de dinero a los bancos, principalmente de Estados Unidos, colocando en América Latina entre 1979-1980 300 mil millones de dólares, conforme a las estadísticas del Banco Mundial, la Cepal y el Fondo Monetario.

Por otra parte, la tasa de interés durante décadas fue del $6 \%$ al $6,9 \%$ como máximo, según tasa líbor de Londres y luego por necesidades de los Estados Unidos, la Federal Reserve (Banco Central) aumentó la tasa de un $6 \%$ al $22 \%$ en un año, lo que significó que América Latina pagó, entre 1980-1996, 648 mil millones sólo en servicios y hoy la deuda es de más de $700 \mathrm{mil}$ millones. Esto debemos calificarlo como un anatocismo desenfrenado.

Han dicho el profesor Bonilla, de Colombia, y la profesora Ortiz Ahlf, de México, que:

... la deuda externa, como ampliamente se ha reconocido, está destruyendo todo, la posibilidad de desarrollo de países subdesarrollados, la producción interna, el nivel de vida de las poblaciones, el empleo, los presupuestos nacionales se restringen cada vez más y se limita en ocasiones a los gastos que ocasiona la deuda. Se destruyen los sistemas de educación y salud, las ciudades se deterioran y la miseria golpea, hasta la misma naturaleza entra en sistema progresivo de destrucción. El pago de la deuda externa no permite el cuidado de nada, ni de la vida humana ni de las condiciones de vida naturales.

Los servicios de la deuda se llevan cinco veces más que el presupuesto de educación, o cinco o seis veces más que el presupuesto de salud. El ex secretario de Estado de Estados Unidos, Henry Kissinger, ha reconocido que ninguno de los países deudores podrá simultáneamente pagar su deuda y lograr el crecimiento políti$\mathrm{co}$, económico y social. Esto es una verda- dera usura y se hace extensivo también a la Europa oriental.

\section{LA DEUDA EXTERNA ARGENTINA EN CIFRAS}

La deuda total del Estado argentino está llegando a los 120 mil millones de dólares y las provincias argentinas padecen una deuda pública externa de 10 mil millones, calculada a fines de marzo de 1999 , mientras que el endeudamiento privado asciende a otros 40 mil millones. La incidencia dentro del presupuesto es grave: el pago de los intereses de la deuda es un monto mayor a lo asignado en conjunto a educación, salud y las jubilaciones de un millón 300 mil personas, que a agosto de 1999 ascendian a la suma de 8 mil 500 millones de dólares. A fines del año 2000 se superó el $50 \%$ del producto bruto interno, cuando lo aconsejable era no superar el $30 \%$.

En el principio de la década del ochenta, la deuda externa alcanzó a unos $300 \mathrm{mil}$ millones de dólares y se han pagado más de 600 mil millones, en concepto de intereses. El endeudamiento argentino es el que más se ha precipitado a lo largo de los años noventa: hay casi duplicación de la deuda externa pública, a pesar de las privatizaciones y los intereses se han sextuplicado. Vale la pena señalar que la deuda externa total de los países subdesarrollados equivale a una entrega hacia el Norte de 250 mil dólares por minuto.

Corresponde ahora considerar su dimensión jurídica: es notable comprobar que un asunto de esta magnitud, que trata de derechos y obligaciones y que ha sido analizada desde diferentes ángulos: ético, sociológico, político y básicamente financiero, no ha sido abordado desde el punto de 
vista del derecho; parece que la dimensión no tuviera nada que hacer en esta cuestión. Conviene analizar la licitud o ilicitud de ese aumento de tasas. Tenemos que analizar esta situación a la luz de lo que nos enseña el derecho de gentes, tomando en cuenta también su naturaleza jurídica.

La tesis que sustentamos se centra en el valor vinculante de los principios generales del derecho, y por ello del que condena universalmente la usura.

El Consejo Europeo de Investigaciones Sociales para América Latina (Ceisal) tiene un grupo de jurisprudencia de universidades de España, Italia, Francia, Alemania, que se reunieron en 1990 en Brasilia, donde se llegó a la conclusión de que la tesis inicial está basada en la usura y que están comprometidos otros principios como el abuso del derecho, la excesiva onerosidad sobreviniente, la teoría del riesgo, la necesaria equivalencia de las prestaciones, el enriquecimiento sin causa, la buena fe objetiva, la lesión enorme, la teoría de la imprevisión, la corresponsabilidad de los acreedores, etc.

Asistimos, pues, a un proceso de creación normativo inverso al de recepción e incorporación del derecho externo al interno. Acá se trata de la traspolación de reglas iusprivatísticas y por tanto de origen interno nacional, al plano de la regulación de una conducta internacional y ello se opera sobre la base del paralelismo de las razones que alimentan el encuadramiento moral y político de los campos de pertenencia de ambos actos humanos.

La Corte Internacional de Justicia posee una competencia muy especial de emitir opiniones consultivas sobre cualquier cuestión jurídica, a pedido de los órganos de las Naciones Unidas. El doctor Ruda dijo en una oportunidad que si el tema de la deuda llegara a los estrados de la Corte, de 15 jueces, 10 aceptarían la prevalencia de los principios generales en defensa de la situación de los deudores. Asimismo, el hecho de que una cuestión jurídica tenga también contenido político no impediría de ningún modo que la Corte se aboque a su consideración.

Existe una analogía entre la teoria general de los contratos y la de los tratados de derecho internacional, entre los principios que regulan la adquisición de la posesión y del dominio y las normas sobre la adquisición de soberanía territorial.

Con respecto al orden procesal, el derecho de gentes ha tomado principios tales como el de cosa juzgada y los que rigen el onus probandi.

Veamos entonces algunos casos jurisprudenciales:

- Gran Bretaña y Albania en el célebre caso del canal de Corfú, en el que la Corte destacó que no son sólo las normas convencionales y consuetudinarias las que deben aplicarse, sino que hay ciertos principios de humanidad que también tienen valor vinculante. En el caso se trataba del minado de las aguas del canal de Corfú, y las autoridades albanesas, según la Corte, tenían la obligación de respetar consideraciones elementales de humanidad, más absolutas aún en tiempo de paz que en tiempo de guerra.

- El del Senado de Hamburgo actuando, en 1861, como tribunal en el célebre caso "Short Drige", en el que aplicando el derecho común, basado en normas del derecho romano, con respecto al cobro de dinero, estableció que cuando el pago de intereses alcanza el monto del capital inicial, los intereses cesan. Es pertinente su mención porque es exactamente la situación que se da con la deuda externa.

Por otra parte, la Santa Sede ha hecho una apelación, a través de un llamado del 
Papa en la reunión de la $\mathrm{FAO}$, a la condonación de la deuda externa, donde se señaló que el fundamento no sólo es de orden económico y técnico sino ante todo ético, lo que fue avalado por el presidente del Banco Mundial, James Wolfensohn. Sin embargo aclaró que éste sólo representa un $8 \%$ de los acreedores, la mayor parte corresponde a la banca privada.

Asimismo, el presidente del Parlamento Latinoamericano se dirigió a su homólogo del Consejo Episcopal para América Latina (Celam) en los términos siguientes:

... ese llamado se dirige a la conciencia de los acreedores, mientras que nuestra iniciativa formulada en el campo jurídico es un reclamo de justicia en los países que tienen la convicción de haber pagado ya con creces lo que debían.

La exclusión social abruma. De acuerdo con organismos internacionales y con ponderaciones efectuadas por especialistas en la materia, el $20 \%$ de la población mundial más rico percibe el $86 \%$ de los ingresos mundiales; 1.200 millones de seres humanos participan de un $1,3 \%$ del ingreso planetario. El $60 \%$ de la humanidad, vale decir unos 3.600 millones de personas se reparten la migaja del $6 \%$ del total de las riquezas del mundo, según el informe del Banco Mundial de 1998.

Entre tanto, más gente que los muertos durante la Segunda Guerra Mundial anualmente perece por enfermedades curables y por hambre. Se trata, pues, de un genocidio nunca antes cometido, en el que se deben incluir 500 mil niños que fallecen, cada doce meses, como resultado directo de las deudas externas, según ha revelado la Unicef.

\section{CAMINOS DE SALIDA}

Partimos de la premisa de que todo esfuerzo será en vano si se continúa con la subversión de la jerarquía de valores. Al colocar como prioridad lo económico y desalojar la política y la moral de la función de contralor y guía, deviene en grave atentado contra los cimientos de la sociedad. Por lo tanto, se propicia que la Asamblea General de las Naciones Unidas eleve a la Corte Internacional de Justicia el siguiente pedido de opinión consultiva: La Asamblea General de las Naciones Unidas pide a la Corte Internacional de Justicia una opinión consultiva sobre:

- ¿Cuál es el marco jurídico del derecho internacional en el que se sitúan las obligaciones que resultan de la deuda externa y su cumplimiento?

- En particular, ¿qué consecuencias producen sobre dichas obligaciones el aumento imprevisto, en términos reales, de los capitales e intereses?

Esto fue realizado por la República Argentina en 1996, en la Cámara de Diputados de la nación a través de un proyecto de declaración presentado por Alfredo Allende, lo que fue seguido por Venezuela, Brasil e Italia.

¿Cuáles podrían ser las consecuencias de una opinión favorable de la Corte? Por ejemplo, la de abrir posibilidades de defensa procesal en eventuales pleitos contra bienes de países deudores en situación de incumplimiento de pago de intereses.

Debe recordarse, además, que las opiniones consultivas del tribunal de La Haya son vinculantes para todos los organismos del sistema de las Naciones Unidas, entre las cuales se encuentran el Fondo Monetario Internacional y Banco Mundial, con tanta responsabilidad en el manejo de la deuda externa. 
Es preciso recordar que la unidad de toda sociedad reposa en un tríptico de valores: orden, seguridad y poder, pero todos subordinados al valor justicia, cuya base angular reside en el respeto y la dignidad de la persona. Por ende, adquieren cada vez más relevancia los institutos de la buena fe, abuso del derecho, la lesión y la imprevisión como medios de modificar conductas, bilateral o multilateralmente comprometidas.

En el caso de los contratos es totalmente aceptado que éstos deben ser cumplidos porque ello hace a la seguridad jurídica y a la justicia (pacta sunt servanda). Es el principio recogido por nuestro Código $\mathrm{Ci}$ vil en el artículo 1197 pero, seguidamente, el artículo 1198 cobija la doctrina de la imprevisión: un contrato válido, de ejecución diferida o continuada, donde se observa una notable desproporción en desmedro del deudor.

En la materia que nos ocupa coexisten dos sistemas jurídicos y políticos diferentes. El sistema bajo el cual están estructurados los contratos de préstamos que corresponden al derecho anglosajón que reflejan los regímenes jurídicos y políticos de Estados Unidos e Inglaterra, y por la otra parte la organización política y jurídica de los deudores, que corresponde al sistema del derecho civil o del llamado Código Napoleónico.

Sin embargo, se ha puntualizado bien acerca de los cambios favorables efectuados dentro del sistema del common law: las limitaciones de la libertad de contrato para mayor protección del deudor frente a las ventajas ilegales del acreedor, las limitaciones a la propiedad, la necesidad de tener en cuenta el interés social, y en este mismo sistema se respeta la equity, cuyo significado podría concretarse en la aplicación de consideraciones de fairness (limpieza, rectitud) y del fair play (trato o jue- go limpio y justicia frente a la letra del derecho).

En esta misma línea la Conferencia Internacional sobre la Deuda Externa de los Países en Desarrollo (São Paulo, Brasil, 1986) consideró las siguientes conclusiones de carácter jurídico: el análisis de los contratos que instrumentan la deuda externa revela que muchos de ellos son ilícitos, pues violan principios y normas consagradas por el derecho internacional y por el orden jurídico interno, no sólo de los países deudores, sino también de los propios países acreedores. Constituye una violación flagrante de principios básicos de derecho -universalmente reconocidos y aceptados- la inserción de cláusulas que permiten en los contratos la alteración del valor de las obligaciones y de las condiciones de su cumplimiento, por la voluntad unilateral de uno de los contratantes, que son fijadas por la parte acreedora.

En consecuencia, debe ser hecha una amplia revisión de los contratos que instrumentan la deuda externa, eliminándose las cláusulas contrarias a los principios de derecho público y privado, internacional o interno, especialmente las que aseguran a los acreedores la posibilidad de alterar unilateralmente las condiciones y valores de las obligaciones, anulándose sus efectos.

Hay, pues, una fuerte tendencia a excluir el examen de los problemas jurídicos y ver solamente la perspectiva de la voluntad política, una tendencia a no considerar como problema los perfiles jurídicos de las normas, institutos y principios que regulan la materia de la deuda externa y a no hipotetizar que pueden existir graves violaciones de éstos.

Es decir, hay una fuerte tendencia a operar como si el único principio jurídico que hubiera que respetar fuera el pacta sunt servanda, y no sea en cambio nece- 
saria también la corroboración de los contenidos pactados.

Específicamente, en cuanto al encuadramiento jurídico, entiendo que es oportuno tratar de individualizar prevalentemente los puntos de convergencia entre el encuadramiento a nivel del derecho internacional -que regla las relaciones entre las naciones y elabora principios para el nuevo orden económico internacional y para la paz-y el encuadramiento a nivel de los derechos fundamentales, derechos del hombre que han sido reconocidos en las cartas internacionales y en las constituciones como el encuadramiento a nivel de aquellos principios enraizados históricamente y estructuralmente en las relaciones civiles entre las personas y que se extienden desde dicha raíz como núcleos fundamentales de los principios generales del derecho.

Podemos afirmar que se ha producido la rebelión de los hechos y del derecho contra la rígida interpretación de las normas escritas o contratadas. Es el reconocimiento de que, por encima de la letra de la ley y del acuerdo entre partes, existen valores más nobles, como las exigencias de justicia y respeto a la dignidad humana. $\mathrm{Si}$ esas exigencias no fueran respetadas, el orden jurídico estaría siendo violado.

Las normas legales y contractuales que no respeten esas exigencias deben ser revisadas y corregidas.

Debe notarse que los contratos de la deuda externa de los países de América Latina contienen cláusulas que, en su ejecución, agreden las exigencias de justicia y atentan contra la dignidad de las personas humanas, que constituyen una población de 400 millones de habitantes. Esta violación es patente:

- En las cláusulas que conformaron el sistema de intereses variables.

- En el crecimiento vertiginoso de la deuda y su excesiva onerosidad. Del $1 \%$ anual pasó, por decisión del Federal Reserve Board, al 21,5\% anual en 1981. - En la fijación del foro privilegiado.

Hubo entonces un cambio imprevisible en las condiciones objetivas, generando una onerosidad excesiva del deudor. Desde finales de 1982 hasta 1998, América Latina pagó aproximadamente 235 billones de dólares en intereses y su deuda aumentó 50 billones. América Latina, una región subdesarrollada, se convirtió en exportadora de capital, lo que constituye una situación injusta e insostenible.

Otra grave violación de los principios de justicia e igualdad, está contenida en las cláusulas de fijación del foro competente, para decidir sobre las divergencias en cuanto a la interpretación y ejecución de los contratos. En todos los préstamos se exige la fijación del foro de Nueva York u otra ciudad, pero siempre del país acreedor, para decidir sobre cualquier divergencia entre las partes. Juristas, políticos y economistas vienen protestando contra esta práctica. La soberanía de los estados es principio fundamental del derecho internacional y por respeto a esta soberanía un país deudor no puede someterse a ser juzgado por el tribunal de un país acreedor.

Es necesario tener en cuenta otros principios, además del de pacta sunt servanda. No en forma sustitutiva y excluyente, sino coordinada y armónica, para enfrentar con verdadero y correcto enfoque jurídico el problema de la deuda externa.

Hagamos una esquemática y parcial enumeración de los principios:

- El principio de la buena fe. Tiene su fundamento en la propia Carta de las Naciones Unidas, que exige que "los estados deben cumplir de buena fe las obligaciones contraídas". El cumplimiento de las obligaciones contraídas, y el derecho a exigir este cumplimiento, debe ser efectuado de buena fe. Es 
un principio general, tanto del derecho interno como del derecho internacional. La buena fe se aplica tanto al acreedor como al deudor.

La Convención de Viena de 1970, sobre Derecho de los Tratados, vincula el principio pacta sunt servanda con la buena fe, ya que su artículo 26 establece que "todo tratado en vigor obliga a las partes y debe ser cumplido por ellas de buena fe".

Hay dos casos que deben recordarse en este sentido. Uno en la actual Corte Internacional de Justicia y otro en la antigua Corte Permanente de Justicia Internacional.

- En el caso de los intereses alemanes en la Alta Silesia polaca de 1926, la Corte Permanente unió el principio de la buena fe al del abuso del derecho, relacionando ambos principios en un mismo sistema jurídico.

- El de ensayos nucleares; la Corte Internacional de Justicia, en 1974, amplió aún más el ámbito de aplicación del concepto tradicional de buena fe, diciendo que la buena fe era un principio aplicable también al cumplimiento de los deberes que resultaban de obligaciones unilaterales con proyección internacional.

Hay, asimismo, una necesaria relación entre el principio de buena fe y la inadmisibilidad de la usura. La usura es una expresión de inmoralidad económica. Ha sido condenada y sancionada en todos los sistemas jurídicos civilizados. La usura es incompatible con la buena fe. Por eso toda expresión de usura en el pago de la deuda externa viola el principio de la buena fe y limita, condiciona y relativiza la aplicación del principio pacta sunt servanda.

- El segundo principio aplicable es el de la equidad. Nadie duda de que la equi- dad es la justicia del caso concreto. En opinión de Paul Reuter razón y buena fe son términos que, sumados, integran el concepto de equidad. La verdadera equidad implica tratar de manera distinta situaciones diferentes para corregir la desigualdad real. La equidad es ponderación, es equilibrio, es balance. Significa considerar y utilizar las circunstancias específicas en cada situación y apreciar su importancia; significa resolver en caso concreto utilizando el conjunto de elementos aplicables y la totalidad de las circunstancias pertinentes.

- El tercer principio aplicable es el que afirma la necesidad de tener en cuenta las consecuencias que derivan del cambio fundamental de circunstancias. Esto está aceptado en la Convención de Viena sobre el Derecho de los Tratados como causa para dar por terminado un tratado o retirarse de él cuando ese cambio tenga por efecto modificar radicalmente los alcances de las obligaciones que todavía deban cumplirse en virtud del tratado.

- El cuarto principio a aplicar es el del enriquecimiento sin causa. Es éste un principio general del derecho. Nacido en el derecho interno, se ha trasladado al derecho internacional y ocurrió fundamentalmente en el caso de las nacionalizaciones de Europa oriental y en los acuerdos globales de indemnizaciones y es enteramente aplicable a la deuda externa.

- En último término tenemos el principio general de la solidaridad y la cooperación que es fundamental y ha sido adoptado por la Carta de las Naciones Unidas y por su Asamblea General. Un importante sector de la doctrina ha sostenido que son expresiones de la moral internacional. Pero siguiendo a 
Cicerón en su tratado De officiis no podemos negar que muchas injusticias devienen de aplicaciones del derecho limitadas y parciales, que constituyen un abuso y una utilización maliciosa del derecho, y conduce a la negación de ese derecho y de la justicia, que son su necesario e ineludible fundamento. En consecuencia, debemos señalar que es preciso rescatar las condiciones materiales, para hacer posible la existencia de los derechos económicos, sociales y culturales.

En la Convención Americana sobre Preámbulo dice:

No puede realizarse el ideal del ser humano libre, liberado del temor y la miseria, a menos que se creen las condiciones que permitan a cada persona gozar de los derechos económicos, sociales y culturales, tanto como de los derechos civiles y políticos.

Por lo tanto, busquemos los caminos para que no quede en nuestro epitafio la frase "Viví pagando y mori debiendo". 